Human and Animal Health

Vol.60: e17160438, January-December 2017 35http://dx.doi.org/10.1590/1678-4324-2017160438 ISSN 1678-4324 Online Edition
BRAZILIAN ARCHIVES OF

BIOLOGY AND TECHNOLOGY

AN INTERNATIONAL JOURNAL

\title{
Epidemiology Study on P53 (Rs1614984) C>T Mutation in Cigarette Smokers
}

\author{
Dilshad Ahmad ${ }^{1}$. \\ ${ }^{1}$ King Saud bin Abdulaziz University for Health Sciences, Riyadh, Saudi Arabia.
}

\begin{abstract}
Epidemiology data have established that smoking is a prime threat for the cancers, largely lung cancer. Singlenucleotide polymorphisms (SNPs),P53 SNPs have been found to be associated with the predisposition of different cancers. Their decreased expression is reported in breast and lung cancer patients. p53 (rs1614984) had been reported to be linked with the SNPs found associated with breast cancer. The primary aim of this study to determine the association of 53 variant rs 1614984 with the cigarette smokers and smoking related cancers in smokers.

Among the smokers, $38 \%$ were found with CC genotype, 55\% were heterozygous CT and 7\% were TT, respectively. The homozygous TT genotype was seen in lower percentage of smokers (7\%) when compared to non-smokers (8\%) whereas; Significant difference was not observed when encompassed by CC, CT and TT genotypes $(\chi 2=4.892$, $p=0.087)$. However, CC vs CT genotype showed a significant difference between smokers and non-smokers ( $p=0.031$, OR 1.447 (1.035-2.025) and the dominant model CC vs CT+TT was also significantly different among smoker and non-smokers ( $p=0.047$, OR 1.39 (1.004-1.924). Furthermore, smokers are at the risk of developing variety of diseases including lung cancer. Our finding suggests a higher percentage of heterozygous CT genotype in smokers when compared to non-smokers. Therefore, this finding gives a clue that the transition mutation of $C>T$ (rs1614984) may leads to the lung diseases including cancer in smokers. However, there will be a need of more extensive and elaborated study to set down the aspect of p53(rs1614984) $C>T$ in lung cancer among smokers.
\end{abstract}

Key words:p53 (rs1614984), cigarette smokers, lung cancer, Single nucleotide polymorphisms (SNPs)

\footnotetext{
*Author for correspondence: ahmadd@ksau-hs.edu.sa
} 
Ahmad, D.

\section{INTRODUCTION}

Epidemiologic study has published that cancers is a predominant cause of deaths in the world and lung cancer is the second diagnosed factor, accounting $14 \%$ of all cancers. Environmental toxicants, smoke generated mixtures, Unhealthy diet or germline mutationare the main promoter of cancers. Speculation by scientists, the deaths of cancers could be 595,690 in year 2016. Among them 158080 deaths are expected of lung cancer, accounting one in four each death ${ }^{1}$. Lung cancer are confirm and diagnosed in cigarette smoking people ${ }^{1,2}$. It is estimated that 80 to 90 percent lung cancer allocate by smoking ${ }^{3}$.Smokingis the direct contributory factor for lung cancer including trachea, uterine cervix, and colorectal risk. Also a nonsmoker has 20-30\% risk of cancer when lives in surrounding of smokers. It is generally, postulated that Nitro-hydrocarbonfrom cigarette smoke responsible for mutation and changes in anti-oncogenes. Recently there is a great interest and have been studied to investigate the relationship of SNPs including, CYP1A1, GSTM1, Bcl2, Rbandp53. Numerous studies have been attempted on these genes. The international cancer Genome Consortium has established that TP53 is the most frequent mutation gene in human cancer. p53 an anti-oncogene is a tumor suppressor gene, which act like a car breaker, because of its anti-cancer mechanism. The salient role of SNPs in p53 has been studied and outlined the affiliation with cancers ${ }^{4}$. Experts from various discipline of biology have been working hard to comprehend the mechanism of diseases and its associations of SNPs within genes.Mutations in the p53 gene are found in $70 \%$ of lung tumors, the highest rate for any cancer ${ }^{5}$. Also indicated the involvement of p53 in different types of cancers.Among the recent studies on $p 53$ have been found association with cancers. For example, p53 SNP Arg72Pro is found to be associated with invasive phenotype, peritoneal dissemination, distant metastasis, chemoresistance, and poor prognosis in gastric cancer patients. ${ }^{6}$. In a German population based study, it was claimed that p53 Arg72Pro polymorphism is associated with breast cancer susceptibility ${ }^{7}$.In an Ethnic study of polymorphism, individuals with $p 53$ codon 72 heterozygous (Arg/Pro) and recessive homozygous (Pro/Pro) genotypes in comparison with those with $p 53$ wild type homozygous (Arg/Arg) genotypes and individuals with $p 53 \_11 \mathrm{~T} / \mathrm{G}$ and G/G genotypes versus $p 53 \_11 \mathrm{~T} / \mathrm{T}$ genotypes showed significant association with the predisposition of lung cancer ${ }^{8}$. A recent study, reveals that two SNPs in intron 7 of p53 gene namely In.7..14181 $(\mathrm{T}>\mathrm{C})$ and In.7..14201 $(\mathrm{G}>\mathrm{T})$ are significantly associated with the lung cancer ${ }^{9}$.

An inherited predisposition for the development of lung cancer is anticipated the involvement of multiple alleles within a common gene with modest penetration ${ }^{10}$,

${ }^{11}$.Zhou et al. ${ }^{12}$ has illustrated an importance of smoking-gene interactions with lung cancer predisposition. Furthermore, in the context of oncogene interaction with lung cancer, the impetus of this study was to examine the affiliation of $p 53$ variant rs1614984 $(\mathrm{C}>\mathrm{T})$ with the cigarette smokersin local population to predict the risk of related cancers.

\section{MATERIAL AND METHODS}

A total 300 biological samples from smokers (SM) of age $\geq 18$ years with mean 33 and S.D. 3.5 and matched non-smokers (NSM) were recruited locally and collected for the epidemiological study. In the present study we have used structured questionnaire and the Ethical clearance from Riyadh, Saudi Arabia. Allparticipants were selected from Riyadh region of Saudi Arabia. 
p53 gene mutation among cigarette smokers

DNA Extraction:Genomic DNA was wrenching out carried using predesigned TaqMan ${ }^{\circledR}$ assays as determined accordingly (Applied Biosystems as Assays-byDesign $^{\mathrm{TM}}$ ). The PCR cyclic conditions were set first for 2 minutes at $50^{\circ} \mathrm{C}$ and then 10 minutes at $95{ }^{\circ} \mathrm{C}, 20 \mu \mathrm{l}$ PCR reactions were run for 40 cycles of amplification and denatured at 92 deg. / 15 seconds, 62 deg. /60 seconds. Analysis of Genotype frequency deviations were analyzed by $\chi 2$ test using the SPSS version in previous study ${ }^{13}$.

\section{RESULTS}

After the survey of the region, It is predicted that this is the first study of p53 (rs1614984) in Middle East cohort, which examined the association of in the $p 53$ gene polymorphism with smokers(SM) and non-smokers (NSM).

\section{Analysis of p53 (rs1614984) polymorphism for association with lung cancer risk:}

Integrated data of total subject (300 SM and $300 \mathrm{NSM}$ ) were recruited for genotypic distributions of $p 53$ (rs1614984) (C> T). Statistically analysis using $\chi 2$ test revealed $46 \%$ for the CC, $46 \%$ for the heterozygous CT status, and $8 \%$ for the TT, respectively. Interestingly TT (homozygous) genotype was observed one percent higher in NSM (8\%) in comparison of SM (7\%).Heterozygous CT genotype was noted $9 \%$ lower inNSM (46\%) when collate withSM (55\%) whereas homozygous dominant CC genotype was shown $8 \%$ more in NSM than SM (38\%). Consequently, No Significant difference was observed among CC, CT and TT genotypes in SM and NSM

$\left(\chi^{2}=4.892, p=0.087\right)$. Also, allele $\mathrm{A}$ was not found to be a significant factor associated with smokers $(\chi 2=1.513, p=0.219)$ (Figure-2). Taking into account, these groups were combined before further statistical analysis (Table-1). After combining groups, $\mathrm{CC}$ vs. $\mathrm{CT}$ and $\mathrm{CC}$ vs. CT+TT genotypes revealed significant difference between SM and NSM (OR, 1.447 (95\% CI 1.035-2.025), $p=0.031$; OR 1.39 (95\% CI 1.004-1.924), $p=0.047$ respectively). Other models CC vs TT, CT vs TT and recessive model TT vs CT+TT did not showed any significant differences ( $p=0.85$, 0.32 and 0.39 , respectively) (Table-1). Frequency of allele $\mathrm{C}$ and $\mathrm{T}$ examined for further study. $\mathrm{C}$ and $\mathrm{T}$ allele observed value were of 0.69 and $0.66 ; 0.31$ and 0.35among Smokers andnon-smokers respectively. Neither the $\mathrm{T}$ allele nor the $\mathrm{C}$ alleles were found significantly associated with smokers. However a higher percentage of $\mathrm{CT}$ and lower percentage of $\mathrm{CC}$ genotypes smokers suggests that transition mutation of $\mathrm{C}$ allele to $\mathrm{T}$ and heterozygous condition favor the smoking behavior. Furthermore, our data showed that cigarette smoking favor a circumstance for $\mathrm{C}$ to $\mathrm{T}$ transition and heterozygous condition at rs 1614984 in $p 53$ gene. 
Table-1:OddsRatiowith 95\% CIof p53(rs1614984) gene insmokers

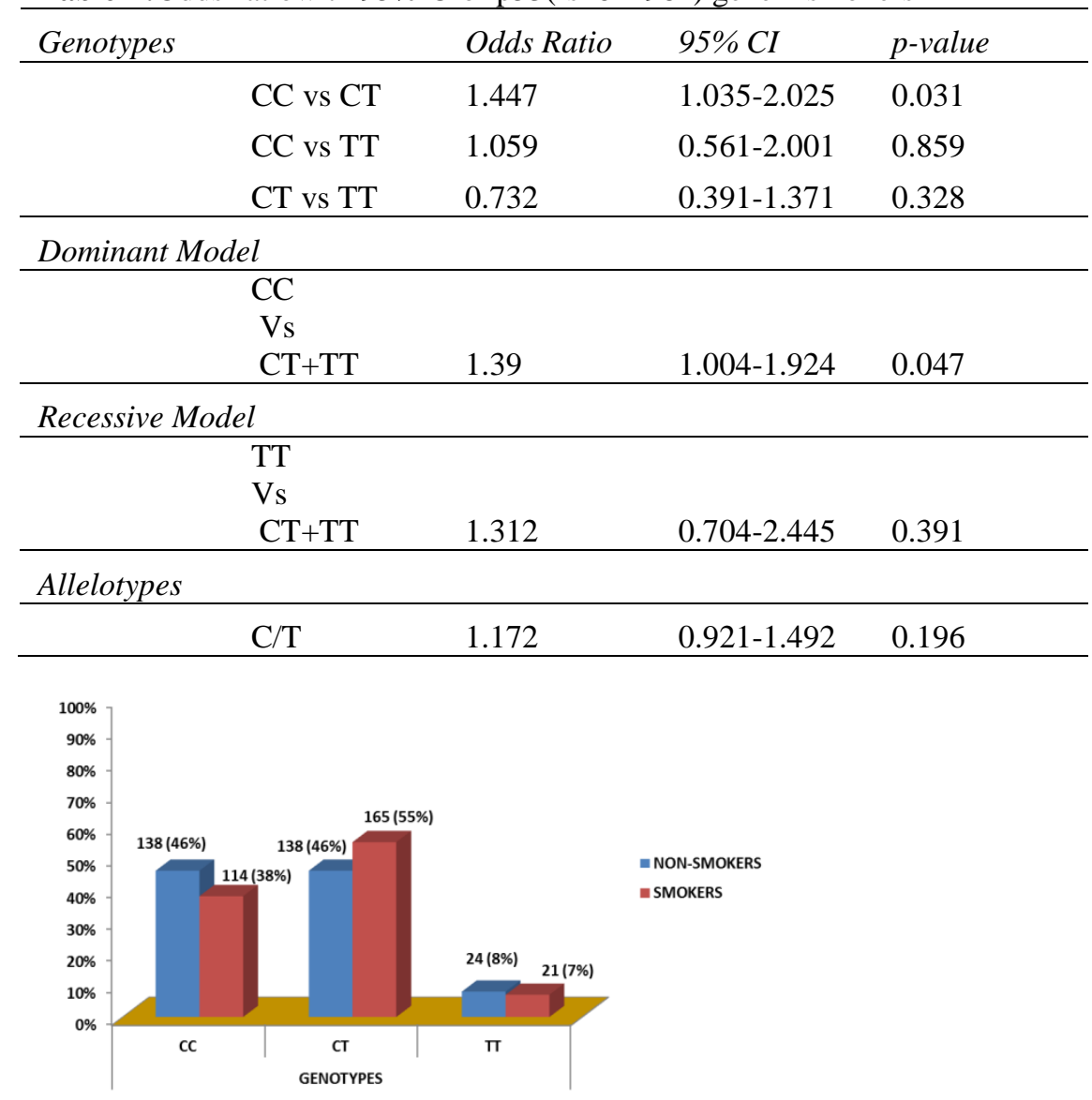

Figure1- $\chi 2(2$ d. f. $)=4.892, p=0.087(p>0.05)$ Not Significant for genotypes

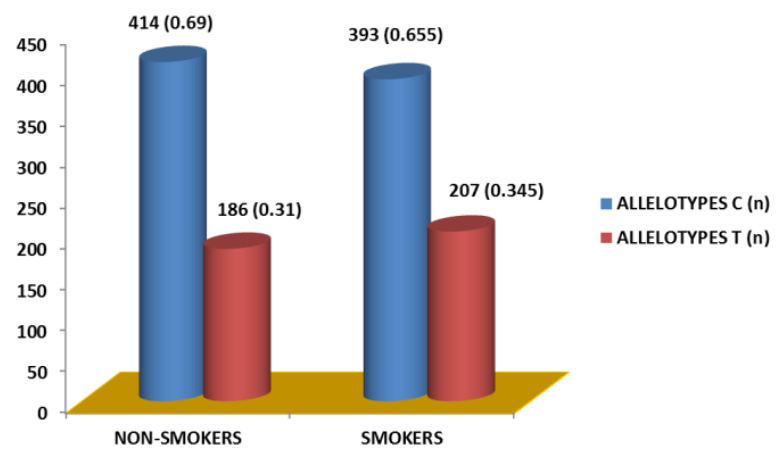

Figure 2- $\chi 2(1$ d. f. $)=1.513, p=0.219(\mathrm{p}>0.05)$ for allelic frequency; (a.f. =allelic frequency)

\section{DISCUSSION}

It is estimated that in men 80 to $90 \%$ of the lung cancer and 40 to $50 \%$ of bladder cancer are attributed to tobacco intake ${ }^{3,14}$. It has been strongly indicated that these types of cancers are associated with cigarette smoking ${ }^{15}$. Also found that cigarette smoking was the chief cause of death after notifying the symptoms of respiratory diseases, Trachea bronchus, pulmonary emphysema, oropharynx, and renal pelvis and for adenocarcinoma of the esophagus in smokers ${ }^{16}$. Smoke from cigarette contain plenty of carcinogenic chemicals, such as nicotine, $\mathrm{CO}, \mathrm{PAH}$ and $\mathrm{N}$ Nitrosamine etc. ${ }^{17}$.Principally, fifty five carcinogenic compounds, including amines, 
p53 gene mutation among cigarette smokers

aldehydes, inorganic and organic compounds in smoke have tendency to nick bio molecules and DNA and may cause disorder in gene expression and cancer too ${ }^{18}$.The uncontrolled cell growth in lung tissues kills lung patients and pose a challenge for efforts to extend and improve the lives of these patients. The amount of functioning on all aspect of p53, reflects a key role in early event of lung carcinogenesis. The tumor suppressor gene TP 53 protein is known to be involved in cell growth arrest, DNA defacement repair, cellular senescence and apoptosis in response to cellular stress ${ }^{19}$.Mutation of the p53 gene is one of the most common genetic abnormalities found more than $90 \%$ in small cell cancers and more than 50\% in non-small cell lung cancers ${ }^{8}$. In spite of the fact that cigarette smoking is strongly tied with lung cancer, it is not developed in all ${ }^{20}$.

Based on genetic study, it is documented that an individual perceptivity in carcinogenesis and confer more risk of lung cancer due to cigarette smoking

${ }^{21}$.Therefore the degree of susceptibility to the lung cancer depends on individual variants (single-Nucleotide polymorphism). Inevitability of this has been stipulated with the association of SNPs with lung cancer. SNPs are the resilient source of genetic mutation and contribute to various diseases including lung cancer ${ }^{22}$. p53 rs1614984 C>T found to be linked with rs2909430 one of the SNPs found to be associated with breast cancer ${ }^{23}$. However the same has not been found to be associated with the occurrence of breast cancer ${ }^{23}$. Although, the role of $p 53$ rs1614984 $\mathrm{C}>\mathrm{T}$ is studied in different cancers, to the best of our knowledge, their role in lung cancer is not studied yet.Therefore, for the first time, aimed to study p53variant (rs1614984) C>T in Saudi smokers. The results from this study indicated thatp53 (rs1614984) C>T single-nucleotide polymorphism was not found significantly associated with smokers $(p=0.08)$. Our result are in consistence with the finding of Sprague et al (2007).

\section{CONCLUSIONS}

In account of insufficient literature and studies on the study of p53 (rs1614984) C>T and their association with the lung cancer and imperil activity of smoking supports to our findings. Research on SNPs variants is still in early stage, studies should extend the findings reported here among different cohort. The present study will optimize for researchers on $p 53$ SNPs in smokers and related lung cancer incidence and the mortality.

\section{REFERENCE}

1-ACS, American Cancer Society. Cancer Treatment and Survivorship Facts \& Figures 20122013. American Cancer Society, Atlanta. 2012.

2-Doll R, Peto R, Hall E, Wheatley K, and Gray R. Mortality in relation to consumption of alcohol: 13 years' observations on male British doctors. BMJ. 1994;309, 911-8 (a).

3-International agency for research on Cancer, IARC (1986). Monographs on the evaluation of Carcinogenic Risk of chemicals to human. Vol. 38: Tobacco Smoking. Lyon: International agency for research on Cance.1986; 244-270.

4-Read AP, Strachan T. Human molecular genetics 2. New York: Wiley; ISBN 0-471-330612. Chapter 18: Cancer Genetics. 1999.

5-Hasan TN, B LG, Shafi G, Al-Hazzani AA, Alshatwi AA. Anti-proliferative effects of organic extracts from root bark of JuglansRegia L. (RBJR) on MDA-MB-231 human breast cancer cells: role of Bcl-2/Bax, caspases and Tp53. Asian Pac J Cancer Prev. 2011;12:52530.

6-Shirai O, Ohmiya N, Taguchi A, Nakamura M, Nakamura M, Kawashimaet al. P53, p21, and p73 gene polymorphisms in gastric carcinoma. Hepatogastroenterology.2010; 57, 1595-601. 
7-Tan XL, Popanda O, Ambrosone CB, Kropp S,Helmbold I, von Fournier et al. Association between TP53 and p21 genetic polymorphisms and acute side effects of radiotherapy in breast cancer patients. Breast Cancer Res Treat.2006; 97,255-62.

8-Mechanic LE, Bowman ED, Welsh JA, Khan MA, Hagiwara N, Enewold L, Shields PG et al. Common genetic variation in TP53 is associated with lung cancer risk and prognosis in African Americans and somatic mutations in lung tumors. Cancer Epidemiol Biomarkers Prev.2007; 16,214-22.

9-Phang BH, Chua HW, Li H, Linn, Linn YC, Sabapathy K. Characterization of novel and uncharacterized p53 SNPs in the Chinese population--intron 2 SNP co-segregates with the common codon 72 polymorphism.PLoS.2011;One.e15320.doi: 10.1371/journal.pone.0015320.

10- $\mathrm{Xu} \mathrm{H}$, Spitz MR, Amos CI, Shete $\mathrm{S}$ et al. Complex segregation analysis reveals a multigene model for lung cancer. Hum Genet.2005; 116, 121-127.

11- Shields P, Harris C. Cancer risk and low-penetrance susceptibility genes in geneenvironment interactions. J Clin Oncol.2000. 18, 2309-2315

12- Zhou W, Liu G, Park S, Wang Z, Wain JC, et al. Gene-smoking interaction associations for the ERRC1 polymorphisms in the risk of lung cancer. Cancer Epidemiol Biomarkers Prev.2005; 14, 491-496.

13- Ahmad D, Bekairy A K, Tamimi W. MDM2 (RS769412) G > A Ploymorphism in cigarette Smokers: A Clue for the susceptibility to smoking and lung cancer risk. Asian Pacific Journal of Cancer Prevention.2015;4057-4060.

14- International agency for research on Cancer, IARC.Momographs on the evaluation of Carcinogenic Risk of chemicals to human. Vol. 38: Tobacco Smoking. Lyon: International agency for research on Cancer. 1987; 106-116

15- Doll R, Peto R, Wheatley K, Gray R, Sutherland I. Mortality in relation to smoking: 40 years' observations on male British doctors. BMJ.1994; 309 (6959):901-11. (b)

16- Sasco AJ, Secretan MB, Straif K. Tobacco smoking and cancer: a brief review of recent epidemiological evidence. Lung Cancer.2004; 2:S3-9. Review.

17- Pryor WA, Stone K. Oxidants in cigarette smoke. Radicals, hydrogen peroxide, peroxynitrate, and peroxynitrite. Ann N Y AcadSci, 686: 1993; 12-27.

18- Hecht SS. Lung carcinogenesis by tobacco smoke. Int. J Cancer. 2012 doi: 10.1002/ijc.27816.

19- Fridman JS, Scott WL. Control of apoptosis by P53. Oncogene. 2003; 22, 9030-9040

20-Schwartz AG, Ruckdeschel JC. Familial lung cancer: genetic susceptibility and relationship to chronic obstructive pulmonary disease. Am J RespirCrit Care Med.2006; 173:16-22.

21-Liu G, Zhou W, Christiani DC. Molecular epidemiology of non-small cell lung cancer. SeminRespirCrit Care Med.2005; 26:265-72.

22- Wu Y, Tao H, Tang J, Zhang X,Zhu Y, Liu Z et al . Retrospective Study of Erlotinib in the Treatment of 70 Patients with Non-small Cell Lung Cancer. ZhongguoFei Ai ZaZhi. 2009;12, 1309-11.

23- Sprague BL, Trentham-Dietz A, Garcia-Closas,Newcomb PA, Titus-Ernstoff L, Hampton $\mathrm{JM}$ et al. Genetic variation in TP53 and risk of breast cancer in a population-based case control study. Carcinogenesis.2007; 28, 1680-6. 